\title{
iguana encodes a novel zinc-finger protein with coiled-coil domains essential for Hedgehog signal transduction in the zebrafish embryo
}

\author{
Christian Wolff, ${ }^{1,2,4}$ Sudipto Roy, ${ }^{1,3,4}$ Katharine E. Lewis, ${ }^{1,5}$ Heike Schauerte, ${ }^{2}$ Gerd Joerg-Rauch, ${ }^{2}$ \\ Annette Kirn, ${ }^{2}$ Christian Weiler, ${ }^{2}$ Robert Geisler, ${ }^{2}$ Pascal Haffter, ${ }^{2}$ and Philip W. Ingham ${ }^{1}$ \\ ${ }^{1}$ Center for Developmental Genetics, School of Medicine and Biomedical Sciences, University of Sheffield, Western Bank, \\ Sheffield S10 2TN, UK; ${ }^{2}$ Max-Planck-Institut für Entwicklungsbiologie, Abteilung III, Tübingen 72076, Germany; ${ }^{3}$ Institute \\ of Molecular and Cell Biology, Singapore 117609, Republic of Singapore
}

\begin{abstract}
Signaling by lipid-modified secreted glycoproteins of the Hedgehog family play fundamental roles during pattern formation in animal development and in humans; dysfunction of Hedgehog pathway components is frequently associated with a variety of congenital abnormalities and cancer. Transcriptional regulation of Hedgehog target genes is mediated by members of the Gli zinc-finger transcription factors. The relative nuclear concentrations of Gli activator $\left(\mathrm{Gli}_{\text {act }}\right)$ and repressor $\left(\mathrm{Gli}_{\text {rep }}\right)$ forms, together with their nucleocytoplasmic trafficking, appear to be critical determinants for target gene expression. Whereas such stringent controls of Gli activity are critical in ensuring appropriate levels of pathway activation, the mechanisms by which these processes are regulated remain inadequately understood. Here, using genetic analysis, we show that the zebrafish iguana gene product acts downstream of the Smoothened protein to modulate Gli activity in the somites of the developing embryo. Positional cloning reveals that iguana encodes the zebrafish ortholog of Dzip1, a novel zinc-finger/coiled-coil domain protein that we show can shuttle between the cytoplasm and nucleus in a manner correlated with Hedgehog pathway activity.
\end{abstract}

[Keywords: Iguana; Gli; hedgehog signaling; zebrafish; muscle; DzipI]

Supplemental material is available at http://www.genesdev.org.

Received December 23, 2003; revised version accepted April 29, 2004.

During animal development, cell fates are specified in response to inductive signals that emanate from discrete sources within the developing embryo. A rather limited number of families of signaling proteins have been implicated in these inductive processes, the complexity of the range of responses they induce reflecting the importance of both cellular context and signal strength. The multiple roles of Hedgehog (Hh) family proteins in animal development exemplify the way in which the same signals can be reiteratively deployed to direct a variety of developmental processes (for review, see McMahon et al. 2003). The myotome of the zebrafish embryo presents a relatively simple paradigm for the analysis of cell-fate specification by $\mathrm{Hh}$ signaling, having the advantage of

\footnotetext{
${ }^{4}$ These two authors contributed equally to this work.

${ }^{5}$ Present address: Department of Anatomy, Downing Street, Cambridge CB2 3DY, United Kingdom.

${ }^{6}$ Corresponding author.

E-MAIL p.w.ingham@sheffield.ac.uk; FAX 44-0-114-222-2788.

Article published online ahead of print. Article and publication date are at http://www.genesdev.org/cgi/doi/10.1101/gad.296004.
}

being readily amenable to genetic analysis. Using mutants and morphants (morpholino antisense oligonucleotide-injected embryos) to manipulate Hh-signaling activity, we have previously shown that different levels of $\mathrm{Hh}$ signaling specify distinct muscle-cell identities within the somites of the zebrafish embryo in a defined temporal sequence (Wolff et al. 2003). Early in embryogenesis, so-called adaxial cells that flank the notochord segregate into two different kinds of slow-twitch muscle fibers that differentiate in distinct regions of the myotome. The superficially located slow-twitch muscle fibers (SSFs) develop in response to low levels of Hh signaling emanating from the notochord, whereas medially located MP cells, characterized by their expression of high levels of the homeobox containing Engrailed (Eng) proteins, are specified by maximal levels of $\mathrm{Hh}$ activity. Later in development, myoblasts of the fast-twitch lineage located close to the notochord and surrounding the MPs are induced to express low levels of Eng proteins and differentiate into MFFs (medial fast fibers) in response to intermediate levels of Hh signaling (Wolff et al. 2003). 
Understanding how the same Hh signal can elicit multiple cellular responses in this way requires a detailed knowledge of the mechanism by which the signal is transduced. Much of what is currently known about the Hh-signaling pathway is based upon its genetic analysis in Drosophila (for review, see Ingham and McMahon 2001). Hh signal, released by the Dispatched (Disp) protein from secreting cells, binds to the Disp-related receptor protein Patched $(\mathrm{Ptc})$ in responding cells, thereby relieving the Ptc-mediated inhibition of Smoothened (Smo), a serpentine protein essential for transduction of all Hh-signaling activity. Activated Smo signals to the transcription factor Cubitus interruptus (Ci) via a direct interaction with Costal-2, a component of a multimeric complex that includes $\mathrm{Ci}$ and the serine threonine kinase Fused (Fu; for review, see Kalderon 2004). Ci acts as a bipotential transcription factor that can repress as well as activate $\mathrm{Hh}$ target genes. The repressor form is generated by limited proteolysis of the full-length protein, a process promoted by PKA-mediated phosphorylation, that is, in turn, potentiated by interaction with the Cos/ Fu complex. Interaction with Costal-2 and a fourth intracellular component, Suppressor of fused [Su(fu)] also regulates the nuclear import of both the activator and repressor forms of $\mathrm{Ci}$. It is the balance between these activator and repressor forms of $\mathrm{Ci}$ within the nucleus of a given cell that ultimately determines the specific target genes that the cell expresses in response to a particular level of Hh-signaling activity.

Targeted inactivation of murine orthologs of the Drosophila Hh-signaling pathway components has established that the mechanism of $\mathrm{Hh}$ signaling has been highly conserved through evolution (Chiang et al. 1996; Goodrich et al. 1997; Zhang et al. 2001; Caspary et al. 2002; Kawakami et al. 2002; Ma et al. 2002). Of the principal components of the pathway identified in the fly, only vertebrate orthologs of costal-2 have yet to be described. One other notable difference, however, is the presence of three homologs of $c i$ in vertebrates, designated Gli1, Gli12, and Gli3, each of which seems to perform a subset of the functions subsumed by ci (Mo et al. 1997; Matise et al. 1998; Park et al. 2000; Buttitta et al. 2003; Motoyama et al. 2003). This picture has been confirmed by studies of the midline class of mutants in the zebrafish (Brand et al. 1996; van Eeeden et al. 1996) that have been shown to inactivate the shh, (Schuarte et al. 1998), disp1 (Nakano et al. 2004), smo (Chen et al. 2001; Varga et al. 2001), gli1 (Karlstrom et al. 2003), and gli2 (Karlstrom et al. 1999) genes. In addition, the use of morpholinos has provided the first in vivo evidence for a conserved function of $\mathrm{Fu}$ and $\mathrm{Su}(\mathrm{fu})$ in regulating Gli activity (Wolff et al. 2003).

Previous studies of another zebrafish midline mutant, iguana (igu), have highlighted several phenotypic traits that it shares with the gli1 (dtr) and gli2 (yot) mutants (Karlstrom et al. 1996; Kondoh et al. 2000; Odenthal 2000), suggesting a link between igu function and Gli activity. Here, using genetic analysis, we adduce evidence that igu acts downstream of Smo to regulate Gli protein function. By adopting a positional cloning ap- proach, we have isolated the igu gene and found that it encodes a novel protein with a single zinc-finger and coiled-coiled domain that can shuttle between the cytoplasm and the nucleus. We discuss the role of igu in $\mathrm{Hh}$ signaling in the light of these findings.

\section{Results}

igu mutant embryos display aberrant $\mathrm{Hh}$ pathway activity

In most developmental and pathological contexts, the response of cells to $\mathrm{Hh}$ signaling is marked by an upregulation of ptc transcription. In the zebrafish embryo, ptc1 up-regulation is prominent in the adaxial slow muscle precursors of the paraxial mesoderm as well as in the ventral portion of the neural tube /Concordet et al. 1996), two cell populations in which Hh signaling plays a major role in cell-fate specification. We found that embryos mutant for igu display a significant expansion of the spatial domain of $p t c 1$ expression in the paraxial mesoderm from the end of gastrulation onward (Fig. 1A,B). Despite this ectopic expression, however, the levels of ptc1 transcript accumulation, both in the adaxial cells and the neurectoderm of igu mutants, are initially reduced relative to their wild-type siblings (Fig. 1A,B). During somitogenesis, however, the ectopic expression becomes progressively more pronounced, such that by $24-\mathrm{h}$ post fertilization (hpf), ptc1 transcript levels are substantially elevated and the expression domain is expanded both in the somites and in the neural tube (Fig. 1C,D; data not shown). Reflecting this altered pattern of ptc1 expression, the specification of Hh-dependent musclecell types is also aberrant in igu mutants. SSFs, normally induced by relatively low levels of Hh activity are reduced in numbers, whereas MPs, induced by high levels of Hh activity, are completely absent from the anteriormost somites (Fig. 1E,F; data not shown). In the remainder of the somites, MPs are reduced in number and exhibit lowered levels and delayed onset of Eng expression (Fig. 1G,H). In contrast to this depletion of Hh-dependent slow lineage cell types, MFFs, the later Hh-induced subset of fast-twitch fibers, are substantially increased in numbers (Fig. 1G-J). Hence, mutation of the igu gene has two diametrically opposed effects on the specification of cell types induced by different levels of $\mathrm{Hh}$ at distinct developmental stages - a reduction in those induced early, with a partial elimination of those requiring maximal signaling activity, followed by a uniform expansion of later induced cell-types requiring intermediate levels of $\mathrm{Hh}$.

igu mutations act downstream of sonic hedgehog, smoothened and Protein Kinase A

The loss of Hh-dependent cell types could reflect a reduction of signaling activity in igu embryos or an inability of mutant cells to respond to Hh signals. To distinguish between these possibilities, we analyzed the response of igu mutants to ectopic Shh activity. In wild- 

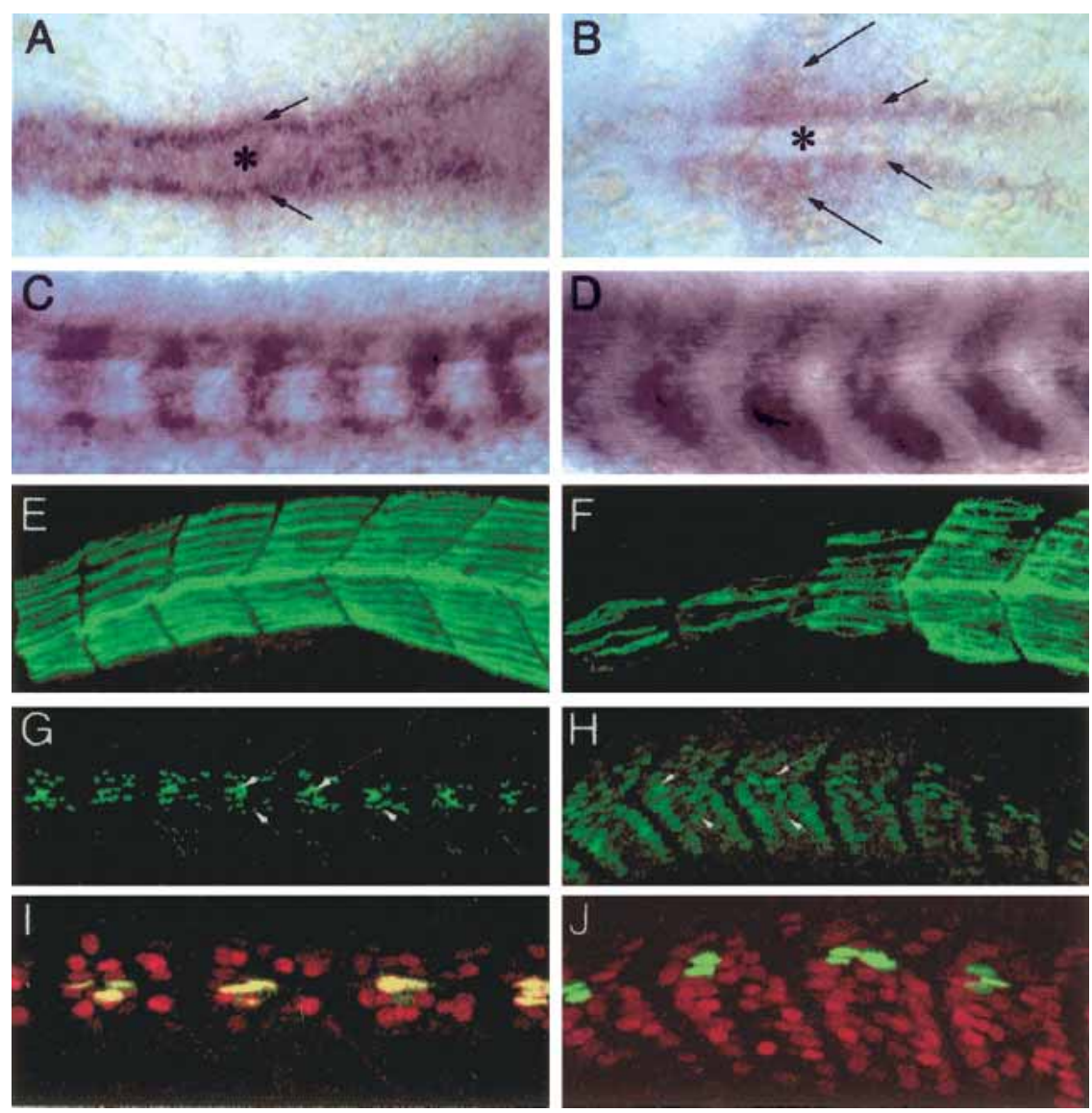

Figure 1. Aberrant $\mathrm{Hh}$ signaling and misspecification of muscle cell-types in igu embryos. (A) ptc1 expression in adaxial cells (arrows) and neural plate (asterisk) of a wild-type embryo. (B) ptc1 expression in a similar stage igu mutant embryo. Note the reduction in expression in adaxial cells (small arrows) and neural plate (asterisk) and ectopic expression in paraxial mesoderm (long arrows). (C) ptc1 expression in the myotome of a wild-type embryo. $(D)$ Expansion in ptc1 expression in the myotome of an igu mutant embryo. (E) Pattern of SSFs in the anteriormost somites of a wild-type embryo labeled with anti-slow MyHC antibodies. $(F)$ Reduction in SSFs in the anteriormost somites of an igu mutant embryo labeled with anti-slow MyHC antibodies. (G) MPs (long arrows) and MFFs (short arrows) in the medial myotome of a wild-type embryo labeled with anti-Eng antibodies. (H) MPs (long arrows) and MFFs (short arrows) in the medial myotome of an igu mutant embryo labeled with anti-Eng antibodies. (I) MPs and MFFs in the medial myotome of a wildtype embryo labeled with anti-Eng (red) and anti-Prox 1 (green) antibodies. Prox1 is expressed in all slow-twitch fibers, SSFs, and MPs. (J) MPs and MFFs in the medial myotome of an igu mutant embryo labeled with anti-Eng (red) and anti-Proxl (green) antibodies. $(A, B)$ Dorsal views of $1-2$ somite stage. $(C-J)$ Lateral views of 24 hpf stage embryos. Embryos depicted in this and all subsequent figures are oriented with anterior to the left, unless mentioned otherwise.

type embryos injected with Shh mRNA, most of the cells of the myotome are transformed to the MP fate (Currie and Ingham 1996; Hammerschmidt et al. 1996; Bladgen et al. 1997; Du et al. 1997); in contrast, the myotomes of similarly injected igu embryos show no such transformation (Fig. 2A-C). Thus, the ability of cells to respond to Shh activity appears to be compromised in igu mutants.

Despite the partial loss of some Hh-dependent muscle cell types in igu mutants, the very same cell types that are completely absent from embryos lacking Shh activity (MPs and MFFs) or Smo activity (all slow-lineage muscles and MFFs), can be partially restored in syu or smu embryos that are also mutant for igu. Moreover, the late gain of Hh-signaling phenotype exemplified by the expansion in numbers of MFFs is unaffected by the loss of Shh or Smo activity from igu embryos (Fig. 2G-L; data not shown). Taken together, these data imply that Igu acts downstream of Shh and Smo to modulate the activity of the intracellular components of the signaling pathway in responding cells. Consistent with this interpretation, we have found that the igu mutation behaves cell autonomously in genetically mosaic embryos (data not shown).

The activity of the Gli transcription factors is negatively regulated by PKA, which acts to promote the cy- toplasmic sequestration of Glil and generate the repressor forms of Gli3 and most likely, Gli2. Accordingly, expression of a constitutively active form of PKA (cPKA) in the zebrafish embryo blocks all responses to $\mathrm{Hh}$ signaling, whereas inhibition of PKA leads to ectopic activation of $\mathrm{Hh}$ target genes and the differentiation of $\mathrm{Hh}$ dependent cell types (Concordet et al. 1996; Hammerschmidt et al. 1996; Fig. 3A). Expression of cPKA in igu mutant embryos suppresses the differentiation of all MFFs as well as MPs (Fig. 3B), implying that the gain of Hh-signaling phenotype is dependent upon Gli activity. In contrast, igu embryos are insensitive to the effects of inhibiting PKA as revealed by their failure to up-regulate ptc1 expression in early somitogenesis stage embryos (Fig. 3, cf. C and D) and by their lack of supernumary MPs (data not shown). Thus, mutation of igu is refractory to the hyperactivation of Gli proteins induced by blockade of PKA activity, suggesting that igu regulates Gli activity downstream of PKA.

igu mutants have distinct affects on Gli1 and Gli2 activities

To elucidate the effects of igu on Gli activity further, we manipulated the expression of Gli1 or Gli2 indepen- 
Wolff et al.
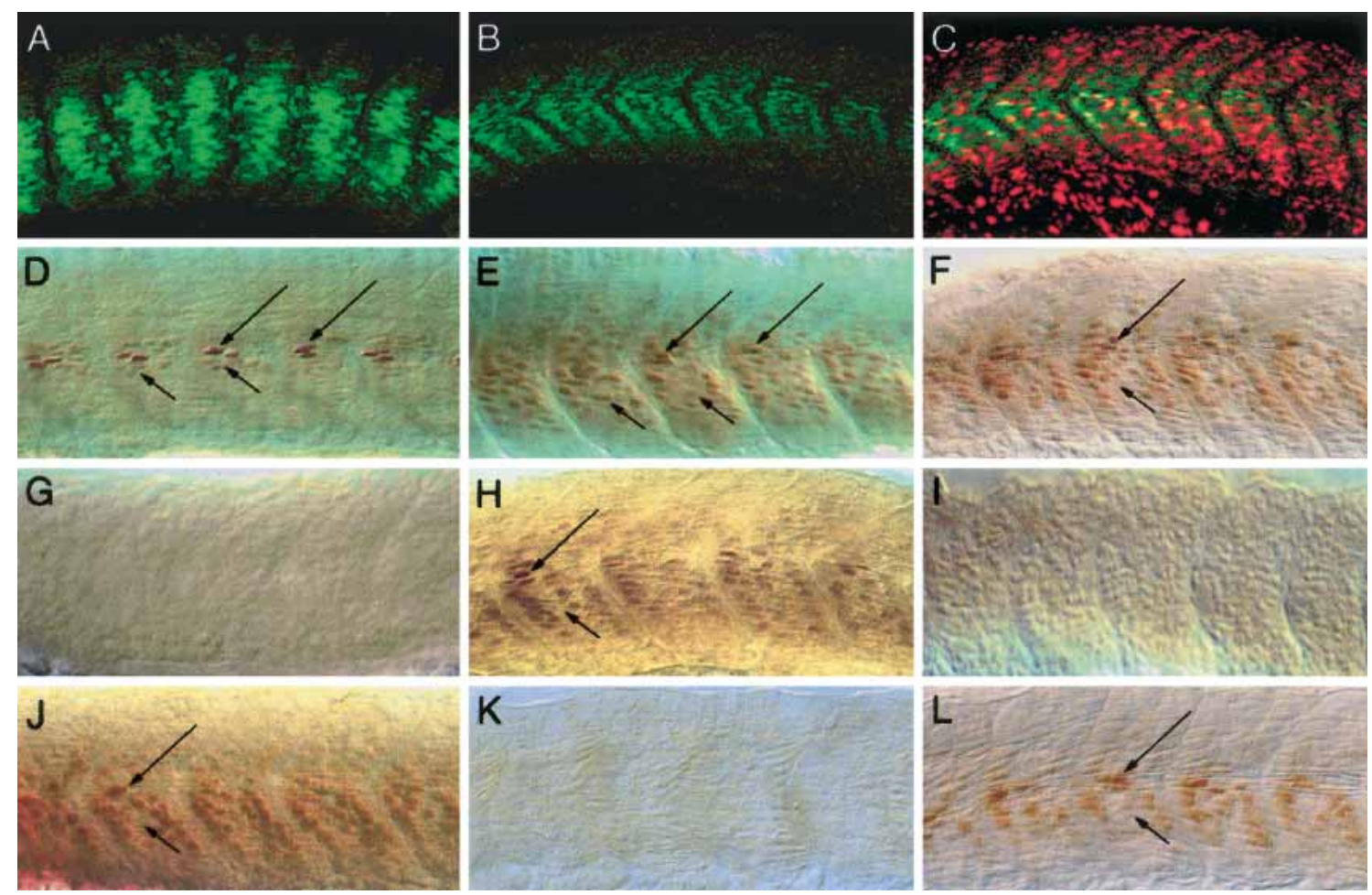

Figure 2. igu mutants are refractory to modulations in Hh signaling activity. $(A)$ A Shh overexpressing wild-type embryo showing expanded MP cell population labeled with anti-Eng (green, $n=51 / 57)$. (B) A Shh overexpressing igu embryo labeled with anti-Eng showing no alteration in cell fates in the myotome $(n=23 / 23)$. (C) The embryo depicted in $B$, showing the nuclear localized $\beta$-galactosidase (red) tracer, whose mRNA was coinjected with that of Shh to ensure proper distribution of injected mRNAs. (D) Pattern of Eng expression in the myotome of a wild-type embryo revealed by histochemistry with anti-Eng antibodies. MPs (long arrows) and MFFs (short arrows) are indicated. (E) Eng expression in the myotome of an iguts294e mutant embryo. Note the expansion of MFFs (short arrows) and a reduction of MPs (long arrows). (F) Similar pattern of Eng expression in the myotome of an igu ${ }^{\text {tm } 79 a}$ mutant embryo. (G) Complete absence of Eng expression from the myotome of a syu mutant embryo. $(H)$ igu-like pattern of Eng expression in the myotome of a syu;igu ${ }^{t s 294 e}$ double-mutant embryo. MPs (long arrow) and MFFs (short arrow) are indicated. (I) Complete absence of Eng expression from the myotome of a smu mutant embryo. (J) igu-like pattern of Eng expression in the myotome of a smu iguts294e double-mutant embryo. MPs (long arrow) and MFFs (short arrow) are indicated. $(K)$ Loss of all Eng expression from the myotome of a wild-type embryo treated with cyclopamine $(n=12 / 12)$. $(L)$ Eng expression is unaffected in an igu ${ }^{\text {tm79a }}$ mutant embryo when treated with cyclopamine $(n=7)$. All panels show lateral views of $24 \mathrm{hpf}$ stage embryos.

dently in igu mutant embryos. In the presence of wildtype igu activity, loss of either Glil or Gli2 alone has little or no impact on the differentiation of the myotome; however, simultaneous elimination of both Gli1 and Gli2 results in complete loss of all Hh-dependent muscle fiber-types, revealing a critical requirement for one or other activating forms of the two proteins in this tissue (Wolff et al. 2003). Strikingly, embryos double mutant for igu and the Glil loss-of-function mutant $d t$, (Karlstrom et al. 2003), lack MFFs and almost all slowtwitch muscle cells (Fig. 4A-D). Moreover, specification of MPs is inhibited even in igu embryos that are hetero-

Figure 3. The igu mutation is epistatic to PKA. (A) A wild-type embryo injected with mRNA encoding cPKA and labeled with anti-Eng antibodies showing loss of Eng expression from the myotome $(n=38 / 47)$. (B) Similar effect of cPKA overexpression in an igu mutant embryo $(n=17 / 21)$. (C) Ectopic expression of ptc1 in a wild-type embryo in response to dnPKA overexpression $(n=34 / 34$, cf. Fig. 1A). (D) The pattern of $p t c 1$ expression in an igu embryo remains unaltered on dnPKA overexpression $(n=16 / 16$, cf. Fig. 1B). $(A, B)$ Lateral views of $24 \mathrm{hpf}$ embryos. $(C, D)$ Dorsal views of 1-2 somite-stage embryos.
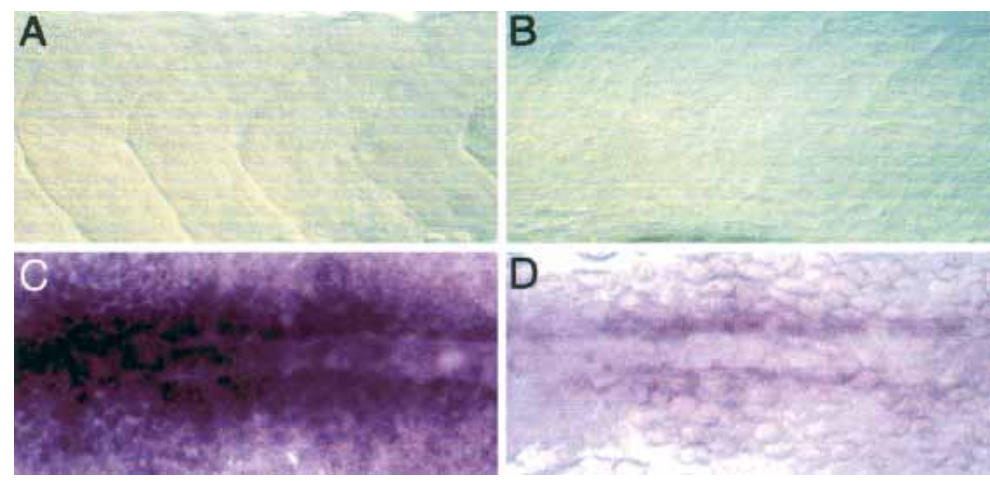

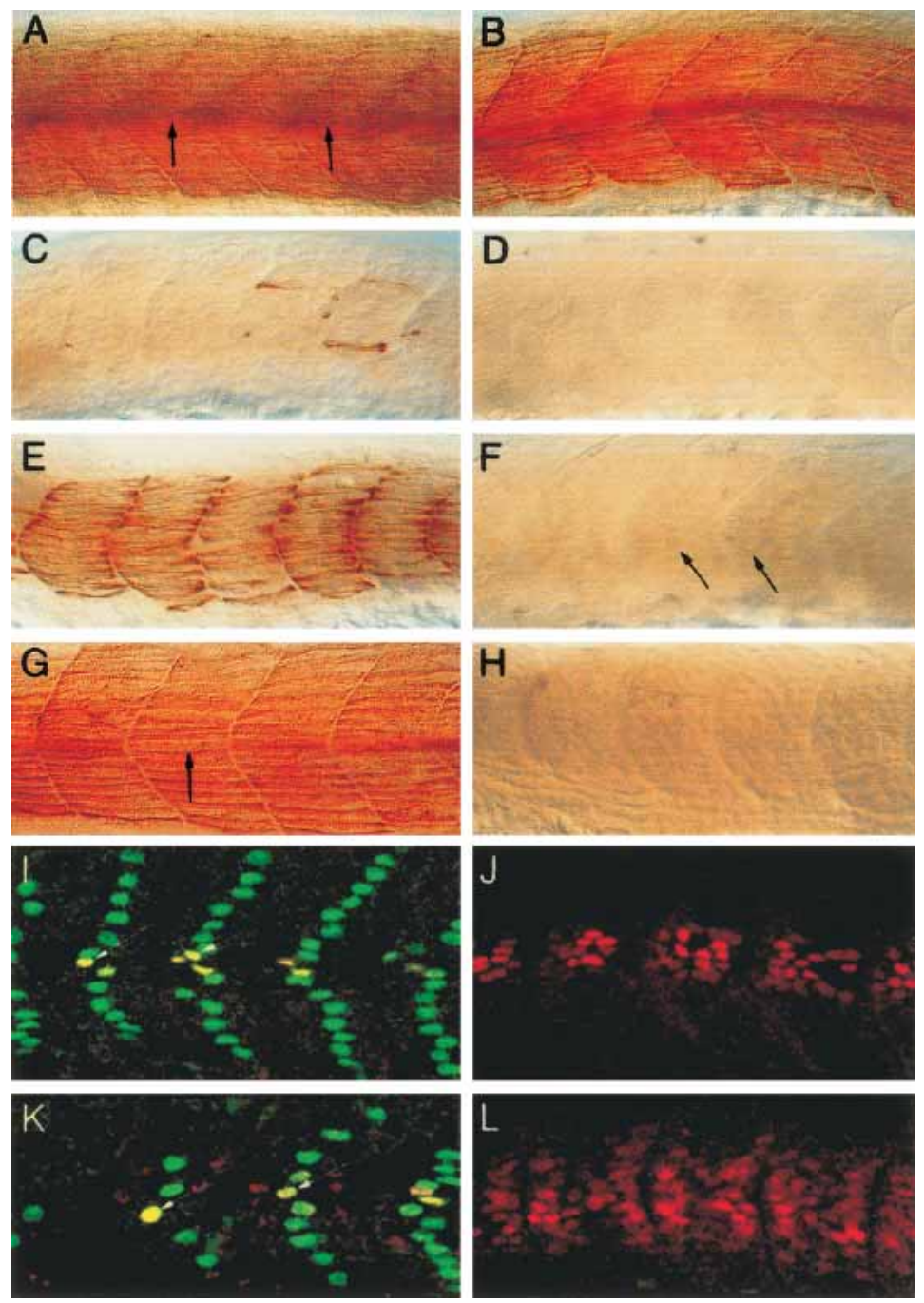

Figure 4. Igu function is essential for proper Gli activity. (A) Slow muscle fibers in the myotome corresponding to somites $5-10$ of a wild-type embryo revealed by histochemical staining with antibodies to slow MyHC. MP cells in the medial region of the myotome are indicated (arrows). (B) Similarly labeled slow fibers of an igu mutant embryo. $(C)$ Slow fibers are almost completely absent from the myotome of an igu; dtr double-mutant embryo. SSF, MP, and MFF pattern in dtr mutants themselves are indistinguishable from wild-type embryos (Wolff et al. 2003). (D) An igu;dtr double-mutant embryo labeled with anti-Eng antibodies showing complete lack of Eng expression from the myotome. (E) An igu;dtr/+ embryo stained with antibodies for slow MyHC, showing a reduction in numbers of SSFs and the absence of the medial bundle of MP fibers. $(F)$ Complete absence of MP-specific high-level Eng expression from the myotome of an igu;dtr/+ embryo. Residual expression of Eng in some MFFs is indicated (arrows). (G) A yot/+ heterozygous embryo labeled with anti-slow MyHC antibodies showing an essentially wild-type like pattern of slow muscle fibers, but with the sporadic loss of the medial bundle of MP cells (arrow). (H) Complete absence of all slow muscle fibers from the myotome of an igu;yot/+ embryo. (I) A wild-type embryo injected with gli2 MOs and labeled with anti-Eng (red) and antiProx1 (green) antibodies, showing mislocation of MPlike cells on the myotomal surface (arrows, $n=14 / 21$ ). (J) The same embryo showing complete lack of MP cells in the medial region of the myotome and an increase in the numbers of MFFs (cf. Fig. 1I). (K) An igu embryo injected with gli2 MOs and labeled with anti-Eng (red) and anti-Proxl (green) showing a reduction in the numbers of SSFs and mislocation of MP-like cells on the myotomal surface (arrows, $n=9 / 12)$. ( $L$ ) The same embryo showing complete lack of MP cells in the medial region of the myotome and a further increase in Eng expression in the MFFs (cf. Fig. 1J). All panels depict lateral views of $24 \mathrm{hpf}$ stage embryos. zygous for $d t r$ (igu; $d t r /+$ embryos, Fig. 4E,F). It follows that Gli2 function is unable to compensate for the reduction or loss of Glil activity in igu mutants. Abrogation of Gli2 activity (by MO-mediated translational inhibition) in igu mutant embryos, in contrast, has relatively little effect on the response of myotomal cells to Hh signaling. SSFs still differentiate, albeit in slightly reduced numbers, whereas the differentiation of MP cells is affected only in so far as they lose their medial location within the somite and appear contiguous with the SSFs (Fig. 4I-L). This implies that Gli1 function not only compensates for loss of Gli2 activity in igu mutants, but is also responsible for the ectopic MFFs characteristic of the mutant embryos. Notably, the level of Eng expression in the MFFs of igu;gli2MO embryos is increased relative to that normally apparent in igu mutant embryos (cf. Figs. 4L and 1J). This may reflect the reduction of Gli2 $2_{\text {rep }}$ activity due to the MO-mediated translational inhibition.

The truncated forms of the Gli2 protein encoded by the yot mutant alleles resemble the endogenous $\mathrm{Gli}_{\text {rep }}$ form and behave as dominant repressors of $\mathrm{Hh}$ target gene expression; consequently, yot/+ heterozygotes are associated with a mild, but discernible reduction of Hhsignaling activity (van Eeden et al. 1996; Karlstrom et al. 1999) and exhibit sporadic loss of MP cells from the myotome (Fig. 4G; see also Wolff et al. 2003). Remarkably, this antimorphic effect of yot is significantly enhanced by the igu mutation; yot/+;igu embryos completely lack all Hh-dependent muscle cells and are indistinguishable from igu;yot double-mutant homozygotes (Fig. 4H).

igu mutants are hypersensitive to variations in the levels of $\mathrm{Su}(\mathrm{fu})$

Gli protein function is modulated by the $\mathrm{Su}(\mathrm{fu})$ protein, which acts both to sequester Glis in the cytoplasm and to inhibit their transcriptional activation activity in the nucleus (for review, see Ingham and McMahon 2001). Consistent with these roles, we have previously shown that morpholino-mediated inhibition of $\mathrm{Su}(\mathrm{fu})$ expression in the zebrafish embryo causes a significant increase in MFFs, an effect that can be attributed to an increase in 
Wolff et al.

Gli1 activity and a loss of Gli2 rep activity (Wolff et al. 2003). Injection of Su(fu) MOs into igu mutants causes a further expansion in the numbers of MFFs, such that they now occupy most of the myotome (Fig. 5, cf. A and B). Conversely, overexpression of $\mathrm{Su}(\mathrm{fu})$, which in wildtype embryos has no discernable effect on muscle differentiation (Fig. 5C,D), results in the near elimination of all Hh-dependent muscle cell types from igu mutant embryos (Fig. 5E,F).

igu encodes a novel protein with a zinc-finger and coiled-coil domain

To elucidate the molecular basis of the igu mutant phenotype, we adopted a positional cloning strategy to isolate the gene. Recombination analysis localized igu to linkage group 6 (LG6), in the vicinity of SSLP markers z17212, z6624, and z9870 (Fig. 6A). Using these markers as a starting point for a genomic walk, we isolated overlapping PAC and BAC clones and constructed a contig comprising several hundreds of kilobases (Fig. 6A). Fine mapping utilizing additional markers derived from the genomic clones placed igu within a critical interval on PAC clone A5 and an overlapping BAC clone D13 (Fig. 6A). Injection of BAC D13 (but not of PACs A1, A5, or BAC C16) into newly fertilized eggs resulted in a partial rescue of the lateral floorplate (LFP; Odenthal et al. 2000) defect manifest in igu mutants (Fig. 6B-D), indicating that the gene mutated in igu is located on this particular genomic fragment. Annotation of this BAC sequence predicted a single ORF in the candidate interval, encoding a protein with a $\mathrm{C} 2 \mathrm{H} 2$-type zinc finger at its $\mathrm{N}$ terminus (residues 209-230), a putative bipartite nuclear localization signal (NLS, residues 172-188), a leucinerich motif matching the nuclear export signal (NES) consensus sequence $\mathrm{LX}_{1-3} \mathrm{LX}_{2-3} \mathrm{LXL}$ (residues 532-541), and a significant number of coiled-coil motifs distributed throughout the remainder (Fig. 6H; Supplementary Fig.
1). Genome sequence database searches revealed extensive synteny between the genomic region of LG 6 containing igu and the region of human chromosome 13 containing the gene encoding DAZ-interacting protein 1 (DZIP1; Moore et al. 2003), a novel protein of unknown biological function exhibiting significant sequence identity to Igu (Supplementary Fig. 1; data not shown). We isolated a full-length cDNA clone encoding the zebrafish Dzip1 homolog; injection of synthetic mRNA derived from this clone (fused at the $5^{\prime}$ end with the cDNA encoding GFP; Fig. 6I) fully rescued the muscle cell-type specification defects of igu mutants (Fig. 6E). Sequence analysis of the two original mutant alleles of igu, together with a third newly recovered in our laboratory, revealed the presence of premature stop codons in all three mutations predicted to result in C-terminal truncations of the Dzip1 protein (Fig. $6 \mathrm{H}$; Supplementary Figs. 1, 2), confirming that igu encodes zebrafish Dzip1. Injection of mRNA derived from a mutant cDNA encoding a truncated form of Igu (corresponding to the iguts294e allele) fused to GFP (Fig. 6J) does not rescue the igu mutant phenotype (Fig. 6G).

igu alleles represent amorphic mutations that completely abolish the function of the protein

All three igu mutant alleles analyzed are predicted to encode truncated proteins retaining the zinc finger and NLS, raising the possibility that their aberrant nuclear localization could contribute to the igu mutant phenotype. To investigate this possibility, we sought to establish the phenotypic consequences of complete loss of igu expression using MO-mediated "knock-down". MOs targeted against the igu translation initiation site surprisingly had no discernible effect on injected embryos (data not shown). We therefore tested two different splice sitetargeted antisense MOs (see Materials and Methods) predicted to induce exclusion of exon2 or exon3 (encoding

Figure 5. (A) A wild-type embryo injected with $\mathrm{Su}(f u)$ MOs exhibiting expansion in the numbers of Eng expressing MFFs (short arrows, $n=15 / 26$, cf. Fig. 2D). MPs are unaffected (long arrows). (B) A similarly injected igu mutant embryo with a striking increase in the numbers of Eng expressing MFFs (short arrows, $n=10 / 14$ ). MPs are unaffected (long arrows, cf. Fig. 2E,F). (C) A $\mathrm{Su}(f u)$ mRNA-injected wild-type embryo labeled with anti-slow MyHC antibodies showing normal pattern of slow muscle fibers $(n=22 / 22)$. (D) A similarly manipulated sibling embryo stained with anti-Eng antibodies showing normal pattern of Eng expression in the myotome ( $n=18 / 18)$. MPs (long arrows) and MFFs (short arrows) are indicated. (E) A Su(fu) mRNA-injected igu
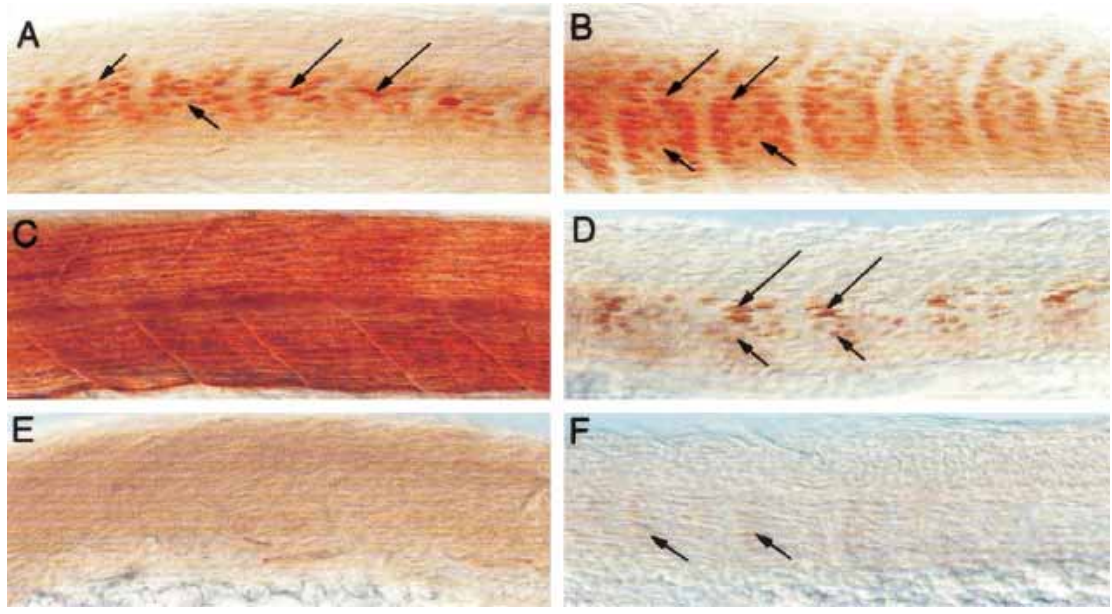
mutant embryo labeled with anti-slow MyHC antibodies showing a dramatic loss of slow muscle fibers $(n=10 / 14$, cf. Fig. 4B). $(F)$ A similarly injected igu embryo showing complete absence of MPs with residual Eng expression persisting in a few MFFs (arrows, $n=16 / 19$, cf. Fig. 2E). 


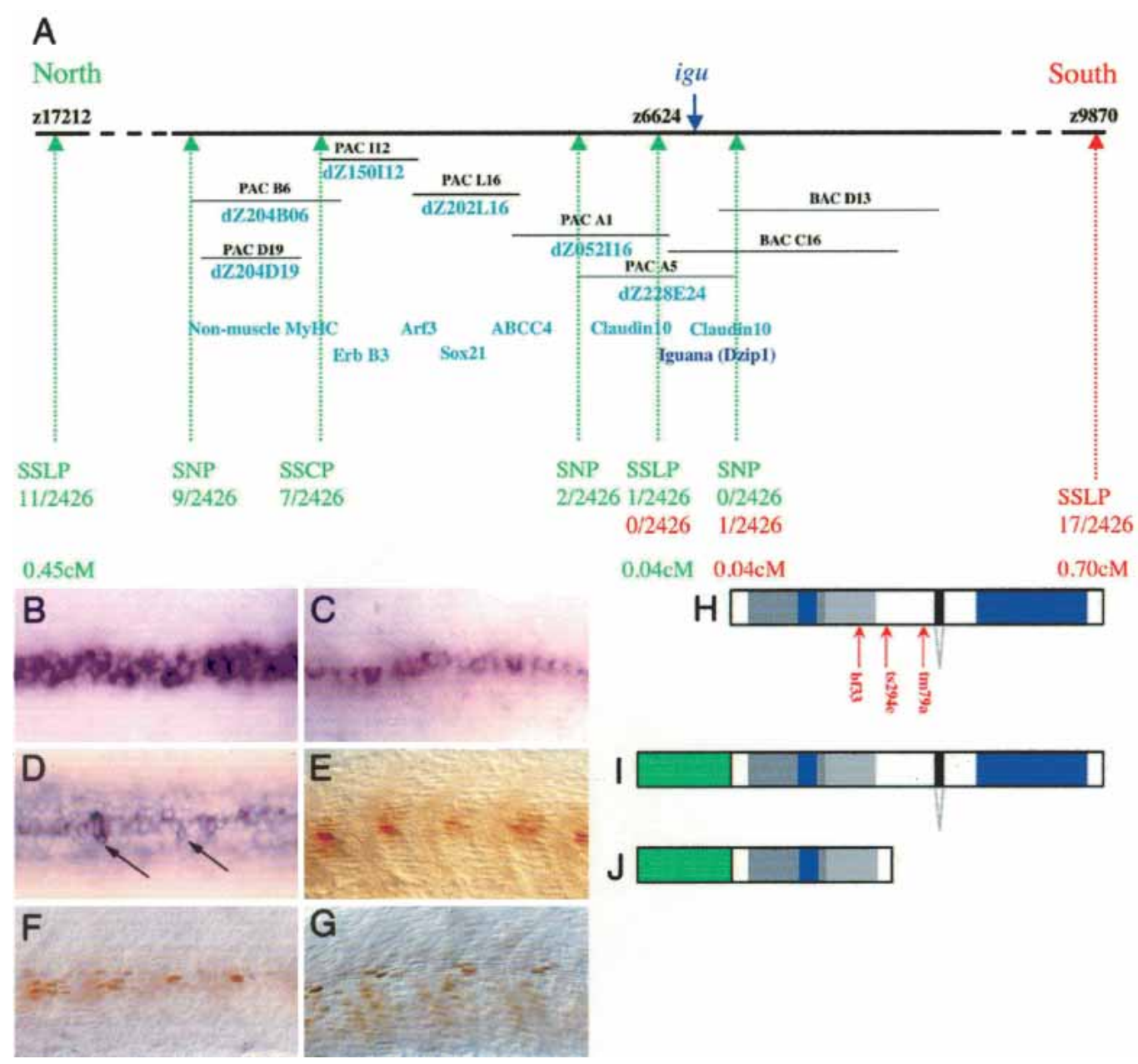

Figure 6. Positional cloning of the igu locus. (A) A genetic map of the igu locus on LG 6, showing the positions of the SSLP (z), SSCP, and SNP markers, genomic clones, and the order of predicted ORFs spanning the interval. Numbers of recombinants and recombination frequencies (in centimorgans [cM]) with markers from the left (north, green) and the right (south, red) directions are displayed. (B) LFP cells of a wild-type embryo showing expression of $f k d 4$. Note that $f k d 4$ is expressed in the LFP as well as in the medial floor plate (MFP) that is flanked by the LFP. $(C)$ In an igu mutant embryo, LFP cells are absent and fkd4 expression remains restricted to a single row of MFP cells. (D) Restoration of patches of $f k d 4$ expressing LFP cells (arrows) in an igu mutant embryo on injection of BAC D13 $(n=16 / 25)$. (E) Wild-type like pattern of Eng expressing muscle cells in the myotome of an igu embryo injected with synthetic mRNA derived from a full-length wild-type igu cDNA fused at the $5^{\prime}$ end to that encoding GFP $(n=19 / 23$, cf. Fig. 2D,E). (F) A wild-type embryo injected with mRNA encoding the mutant Igu protein corresponding to the iguts294e allele tagged N-terminally with GFP showing no changes in the pattern of Eng expression $(n=50) .(G)$ Pattern of Eng expression remains unaffected in igu ${ }^{\text {ts294e }}$ embryos injected with the same mutant mRNA $(n=14)$. $(H)$ Diagrammatic representation of the wild-type Igu protein. The areas shaded in dark and light gray represent $>50 \%$ and $>25 \%$ conservation, respectively, with the human DZIP1 protein (see also Supplementary Fig. 1 ). The N-terminal zinc finger is depicted in light blue and the C-terminal coiled-coil domains in dark blue. The approximate positions where the protein truncates in the three different igu alleles, as well as the position of an alternatively spliced exon (black box) is indicated (see also Supplementary Fig. 1). For reasons of clarity, the putative NES, NLS, and coiled-coil domains around the zinc finger at the $\mathrm{N}$ terminus are not depicted. (I) Diagrammatic representation of wild-type Igu N-terminally tagged with GFP (green box). (J) Diagrammatic representation of C-terminally truncated Igu, corresponding to the igu ${ }^{t s 294 e}$ mutation, N-terminally tagged with GFP (green box). (B-D) Ventral views of 22 somite-stage embryos. (E-G) Lateral views of 24 hpf embryos.

regions $\mathrm{N}$-terminal to the zinc-finger domain and the zinc-finger domain, respectively) during processing of the nascent igu mRNA (Fig. 7A). Injection of either one or a combination of these MOs into wild-type embryos phenocopied all aspects of the Hh-signaling defects apparent in igu mutants, and like the igu alleles, also effectively suppressed the loss of Smo activity induced by cyclopamine (Fig. 7B,C; data not shown). In addition, in- jection of the MOs into the iguts294e embryos themselves had no effect on their mutant phenotype (data not shown), indicating that this does not depend upon the expression of the truncated form of the protein encoded by the mutant allele. Consistent with this, we found that injection of mRNA encoding the GFP-tagged truncated form of the protein into wild-type embryos had no effect on their pattern of muscle differentiation (Fig. 6F). 
Wolff et al.

Figure 7. The igu phenotype represents complete loss-of-function. (A) Diagrammatic representation of the first four coding exons of the igu gene, the relevant nucleotide (and the corresponding amino acid) sequences at the exonic junctions and the splice sites recognized by the two MOs. $(B)$ A wild-type embryo injected with a combination of splice MO1 and MO2 showing an igu-like pattern of Eng expression in the myotome $(n=22 / 27$, cf. Fig. $2 \mathrm{D}-\mathrm{F}) .(C) \mathrm{A}$ similarly injected wild-type embryo with no effect on Eng expression pattern after treatment with cyclopamine $(n=10 / 12$, cf. Fig. $2 \mathrm{~K}, \mathrm{~L})$.
A
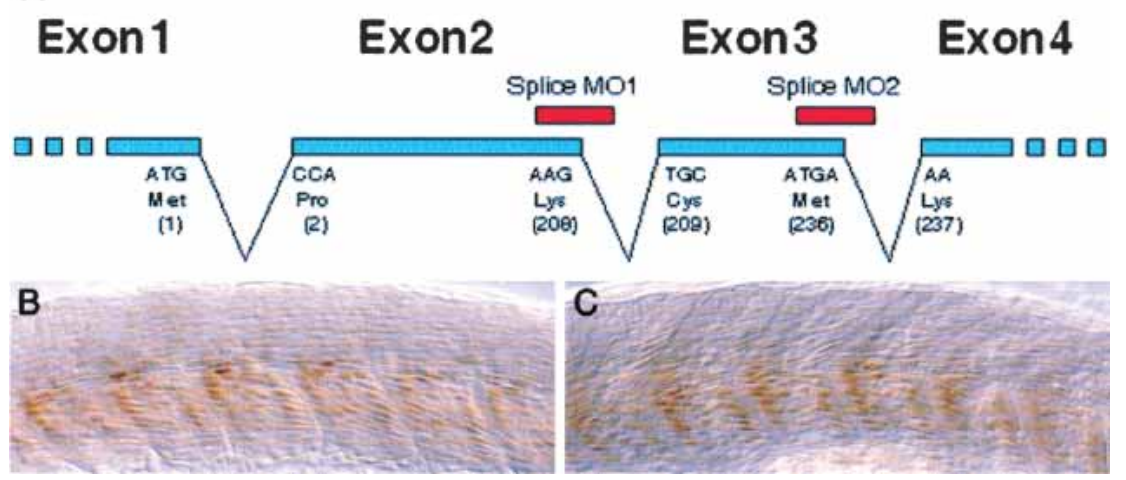

Subcellular distribution of the Igu protein is regulated by PKA activity

Using whole mount RNA in situ hybridization, we found that igu mRNA is maternally deposited and abundant in newly fertilized eggs during cleavage (Fig. 8A). At early and mid-somitogenesis stages, as well as at $24 \mathrm{hpf}$, we observed an essentially ubiquitous and homogeneous distribution of igu mRNA (Fig. 8B,C; data not shown), suggesting that the gene is not transcriptionally regulated by Hh activity. To analyze the subcellular distribution of the Igu protein, we made use of the chimeric cDNA encoding the functional GFP::Igu fusion de- scribed above (Fig. 6I). Due to the relatively deep location within the embryo of Hh-responding cells, these particular cell populations could not easily be imaged to study the subcellular distribution of the GFP :: Igu protein. Instead, we selected cells of the paraxial mesoderm for this assay, as they represent a large, comparatively flat, and more accessible field of cells. Moreover, although not normally exposed to Hh signaling during early somitogenesis, these cells retain the capacity to respond to ectopic activation of the pathway (Concordet et al. 1996; Hammerschmidt et al. 1996; Blagden et al. 1997; Du et al. 1997; Wolff et al. 2003). In such uninduced somitic cells, we found the GFP::Igu protein to be distributed
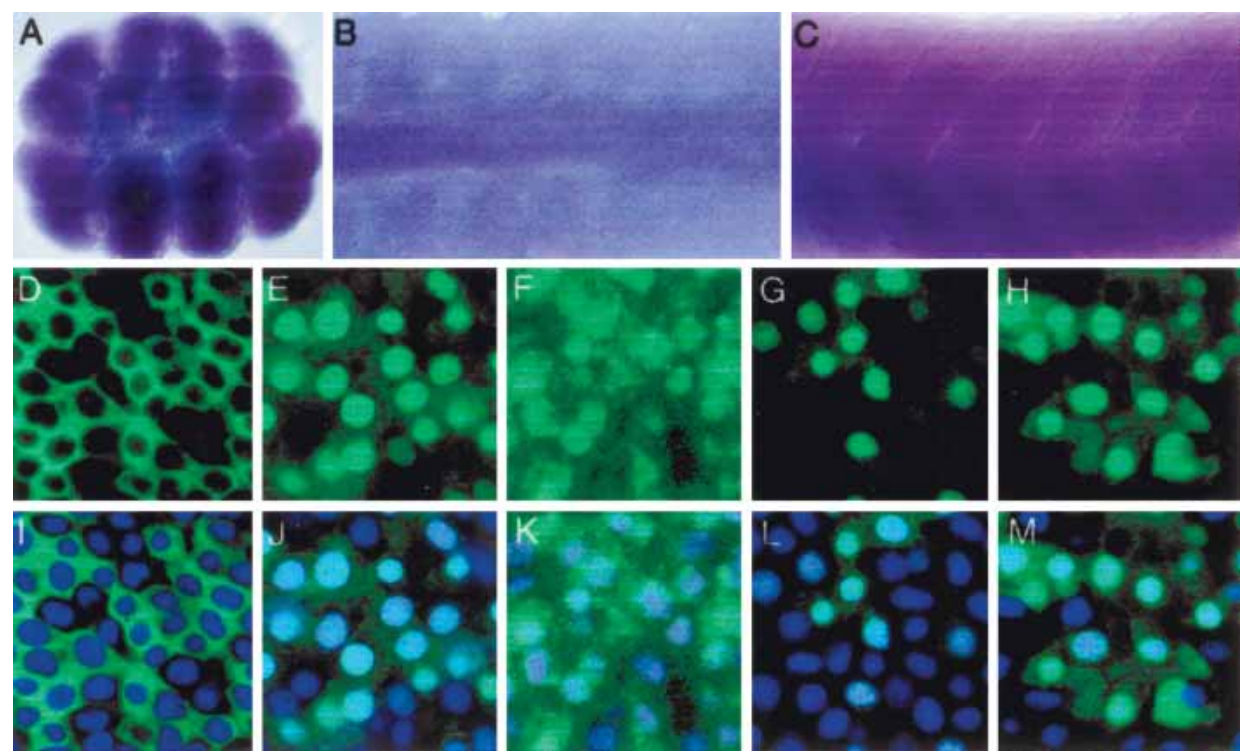

Figure 8. Subcellular localization of the Igu protein, but not the transcription of the igu gene, is regulated by Hh activity. $(A)$ Pattern of maternal igu mRNA distribution in the animal cells of a 16-celled stage embryo. (B) Uniform pattern of zygotic igu mRNA distribution in the midline and somites of a 12-somite stage embryo. (C) Uniform pattern of igu mRNA transcription in the myotome of a 24 hpf embryo. $(D)$ Exclusively cytoplasmic distribution of GFP-tagged wild-type Igu in the paraxial mesodermal cells of a wild-type embryo at the 2 -somite stage $(n=10 / 10)$. This chimeric protein is able to fully substitute for wild-type Igu activity and rescue igu mutant embryos (Fig. 6E). (E) Predominantly nuclear accumulation of the GFP-tagged iguts294e mutant form of Igu $(n=10 / 10)$. (F) Nuclear translocation of GFP-tagged wild-type Igu in response to inactivation of PKA activity $(n=12 / 15)$. $(G)$ Nuclear accumulation of GFP-tagged igu ${ }^{t s 294 e}$ mutant form of Igu remains unaltered on inactivation of PKA activity $(n=10 / 10)$. $(H)$ Nuclear accumulation of GFP-tagged igu ${ }^{t s 294 e}$ mutant form of Igu remains unaltered on overexpression of $\mathrm{Su}(\mathrm{fu})(n=10 / 10)$. (I-M) Superimposition of the GFP images shown in $D-H$ with those highlighting the nuclei in the same preparations after staining with TOPRO-3. $A, B$, and $D-M$ are dorsal views; $C$ is oriented laterally. 
exclusively in the cytoplasm (Fig. 8D,I). Strikingly, however, there is a substantial translocation of the protein into the nucleus in embryos simultaneously injected with dnPKA mRNA (Fig. 8F,K). In contrast, the GFPtagged truncated form of the Igu protein that retains the putative NLS but lacks the putative NES /mimicking that predicted to be encoded by the mutant allele igut $^{\text {ts294e }}$; Fig. 6J) accumulated exclusively in the nuclei of expressing cells (Fig. 8E,J), a distribution that was unaffected by blockade of PKA activity (Fig. 8G,L) or by the overexpression of $\mathrm{Su}(\mathrm{fu})$ (Fig. $8 \mathrm{H}, \mathrm{M}$ )

\section{Discussion}

The most striking feature of the igu mutant phenotype is the paradoxical mix of depletion and ectopic differentiation of Hh-dependent cell types within the embryonic myotome. The reduction in numbers of SSFs and MPs in the anteriormost somites is indicative of an initial attenuation of Hh pathway activity in the paraxial mesoderm, an effect manifested in the reduced levels of ptc1 transcript that accumulate in the adaxial cells of early somitogenesis stage mutant embryos. This effect can be understood as reflecting a change in the balance of Gli2 $2_{\text {act }}$ and Gli2 $2_{\text {rep }}$ activities in favor of the latter; in support of this view, we show that removal of Glil from igu mutant embryos results in the complete elimination of MPs and SSFs (as well as MFFs), indicating that the levels of Gli2 $2_{\text {act }}$, which can normally completely compensate for loss of Glil activity in the myotome (Wolff et al. 2003), are insufficient to mediate even the lowest threshold response to Hh signaling in igu mutants. The insensitivity of igu mutants to blockade of PKA activity argues that igu acts downstream of the phosporegulation of the Gli proteins.

Despite this initial attenuation of pathway activity, all three Hh-dependent muscle cell types can nevertheless differentiate in igu mutant embryos, the late differentiating MFFs actually increasing in number, even in the absence of Shh or Smo function. This ligand independence argues against the possibility that the ectopic induction of MFFs is caused by a spreading of signal across the paraxial mesoderm, as might be predicted to occur, due to the initial low-level expression of the Hh receptor Ptc1 (see Wolff et al. 2003). Rather, in light of the igu; dtr phenotype, we suggest that loss of igu function also causes the low-level constitutive activation of Gli1. Initially, this activity is sufficient to compensate partially for the altered balance of $\mathrm{Gli}_{\text {act }} / \mathrm{Gli}_{\text {rep }}$ activity, thereby accounting for the partial rescue of both MPs and SSFs in the absence of Smo activity. However, as embryogenesis proceeds, transcription of gli1, which like $p t c 1$, is an immediate target of $\mathrm{Hh}$ activity in vertebrates, becomes up-regulated by the constitutive Glil activity (Supplementary Fig. 3), serving to amplify the effect and causing the expansion of the population of late-induced MFFs beyond the normal domain of Hh signaling.

A comparable expansion of MFFs has previously been shown to occur when $\mathrm{Su}(\mathrm{fu})$ activity is depleted. Moreover, we found that this effect is principally mediated by the deregulation of Glil activity, implying that at least in this context, $\mathrm{Su}(\mathrm{fu})$ acts as a negative regulator of Gli1 (Wolff et al. 2003). Studies of Sulfu) activity in tissue culture have suggested that it acts in two ways, both to sequester Gli proteins in the cytoplasm (Ding et al. 1999; Kogerman et al. 1999) and to inhibit their transcriptional activating activity in the nucleus (Cheng and Bishop 2002). In each case, $\mathrm{Su}(\mathrm{fu})$ is thought to mediate this effect by binding directly to the Glis, and specific domains have been defined in both $\mathrm{Su}(\mathrm{fu})$ and Glil that mediate their physical interaction. Thus, the effects of $\mathrm{Su}(\mathrm{fu})$ overexpression in igu mutants are entirely consistent with the notion that deregulated Glil is responsible for the induction of Hh-dependent muscle cell types in these embryos.

The phenotypic similarity and synergistic interaction between igu mutants and $\mathrm{Su}(\mathrm{fu})$ depletion and overexpression could imply a mechanistic similarity between igu and $\mathrm{Su}(\mathrm{fu})$ function. Moreover, we have shown that, like $\mathrm{Su}(\mathrm{fu})$, the Igu protein localizes to the cytoplasm, but translocates to the nucleus in response to the same signal that activates Gli activity. This translocation could be driven by an interaction between Igu and the Gli proteins, as seems to be the case for $\mathrm{Su}(\mathrm{fu})$; according to this scenario, the nuclear-localized Igu might function by modulating nuclear Gli activity. Alternatively, Igu might itself regulate the nuclear-cytoplasmic shuttling of the Glis. Consistent with this notion, we find that like $\mathrm{Su}(\mathrm{fu})$ morphants, igu enhances the dominant effect of yot heterozygotes, suggesting an increased nuclear accumulation of the constitutively active Gli2 $2_{\text {rep }}$ encoded by the yot mutant allele. In this regard, it is striking that the C-terminally truncated form of Igu is constitutively localized to the nucleus. Although this could imply a possible mechanism for the increased activity of both Gli1 as well as the Gli2 $2_{\text {rep }}$ in igu mutants, the fact that the igu mutant alleles are completely recessive, and that misexpression of a truncated form of Igu has no effect on muscle specification argues against this. Furthermore, we have shown that the MO-mediated inhibition of Igu expression has identical phenotypic consequences to the mutant alleles that encode truncated forms of the protein, implying that the increased activities of Glil and Gli2 $2_{\text {rep }}$ are independent of the aberrant nuclear localization of the mutant proteins.

As with $\mathrm{Su}(\mathrm{fu})$, the cytoplasmic retention of Igu may reflect its physical interaction with one or more Gli proteins. Such an interaction could be direct or via an intermediary, perhaps $\mathrm{Su}(\mathrm{fu})$ itself. The molecular structure of the Igu protein is certainly consistent with these possibilities, the single zinc-finger and the coiled-coil domains both capable of mediating protein-protein interactions; however, given the properties of the truncated protein, we would predict that any such Gli interaction would be mediated by the coiled-coil domain. Alternatively, Igu distribution in uninduced cells may be controlled primarily by the NES, which is deleted in the C-terminally truncated form of the protein. Unraveling the details of interactions between Igu and its potential partners, and the requirements for the NLS and NES, 
will be essential in elucidating the basis of its contrasting effects on Gli1 and Gli2 activity.

The Hh pathway is remarkable, in that most of its known components to date have been identified through the systematic analyses of mutations in Drosophila. Despite this scenario, recent biochemical, as well as genetic studies, have led to the isolation of a number of new proteins whose inactivity disrupts $\mathrm{Hh}$ signaling in the mammalian embryo (Chuang and McMahon 1999; Eggenschwiler et al. 2001; Chuang et al. 2003; Huangfu et al. 2003). There is no evidence to date of a role for the orthologs of any of these proteins in regulating Hh signaling in the fly, raising the possibility that they constitute a set of dedicated elements that are required for Hh signal transduction exclusively in vertebrates. Igu represents a new and obligate member of the Hh pathway in the vertebrate embryo whose activity appears to be central to the regulation of the ultimate step in the signaling process, the nuclear access of Gli. We note that a previously uncharacterized gene, CG13617, in the annotated Drosophila genome appears to be a likely ortholog of igu. Whether or not the product of this gene is similarly involved in regulating the nuclear accumulation of $\mathrm{Ci}$ remains to be determined.

\section{Materials and methods}

Zebrafish strains and genetics

The $d t r^{t s 269}, i g u^{t s 294 e}, i g u^{t m 79 a}, s y u^{t 4}, y o t^{t y 119}$, and $s m u^{h i 1640}$ alleles have been previously described (Karlstrom et al. 1996; Schauerte et al. 1998; Chen et al. 2001); the igu ${ }^{b f 33}$ allele was induced by ENU and isolated in an F3 lethal screen at the Center for Developmental Genetics. Because all three igu alleles exhibit similar phenotypic strengths, we have performed all of our functional analysis with iguts294e, unless otherwise mentioned. Double heterozygotes for $i g u^{t s 294 e}$ and $s y u^{t 4}, s m u^{h i 1640}$, yot $t^{t y 119}$, and $d t^{t s 269}$ were generated using standard genetic crosses. The syu;igu and smu;igu double mutant embryos were distinguished by their igu-like morphology and pattern of muscle cells in the myotome and the lack of shh and smo expression, respectively, at $24 \mathrm{hpf}$. Because both $d t r$ and igu genes map to LG6, crosses between heterozygous igu/dtr fish produced $d t r$, igu double homozygotes as well as $d t r$, igu/+ and $d t r /+$, igu mutant embryos resulting from recombination events between the two loci. Whereas $d t r$, igu/+ embryos were indistinguishable from $d t r$ homozygotes, $d t r$, igu and $d t r /+$, igu mutants could be differentiated by their distinct effects on musclecell specification. The identity of $d t r /+$, igu mutants was confirmed by analyzing embryos that derived from crosses between $i g u / d t r$ and igu/+ fish. The severity of the myotomal phenotype of yot;igu double-mutant embryos was indistinguishable from yot homozygotes obtained from crosses of yot/+;igu/+ transheterozygous fish with the numbers of igu-like embryos always short of the expected Mendelian ratio, indicating that yot is epistatic to igu. yot/+;igu embryos were obtained by crossing yot/+;igu/+ transheterozygote fish with igu/+ heterozygotes.

\section{Positional cloning of the igu locus}

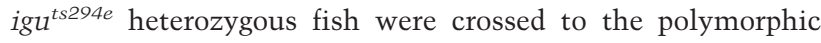
wild-type strain WIK (L11) to produce a reference-mapping cross that was used for linkage analysis. A chromosomal walk was initiated by using the closely linked marker z6624 to isolate $\mathrm{PAC} / \mathrm{BAC}$ clones in the region. Genomic libraries were screened by hybridization of ${ }^{32} \mathrm{P}$-labeled DNA fragments to arrayed filters (C. Amemiya PAC library, RZPD, and CHORI-211 BAC library, BACPAC Resources) or by PCR of pooled clones (C. Amemiya PAC library, RZPD) by use of standard methods. Isolated BAC and PAC clones were sequenced and annotated by the Wellcome Trust Sanger Center as part of their ongoing zebrafish genome sequencing project (http://www.sanger.ac.uk/ Projects/D_rerio). A full-length wild-type dzip1 cDNA clone was identified from the zebrafish EST database (and obtained from the RZPD). Full-length $d$ zip1 cDNA clones were amplified by RT-PCR from embryos homozygous for the three different mutant alleles of igu, and directly sequenced to determine the positions of the lesions. Whereas the igu ${ }^{\text {ts294e }}$ allele harbors a premature stop codon in the cDNA as a consequence of nucleotide substitution, igu ${ }^{\text {tm79a }}$ contains a small deletion and $i g u^{b f 33}$ a small insertion, respectively, that result in translational frame shifts and introduction of premature stop codons (see Supplementary Figs. 1, 2). The GenBank accession number for the sequence of the igu cDNA is AY551927.

\section{Antisense igu MOs}

We utilized three different translation start-site and two splicesite targeted antisense MOs to knock down function of the Igu protein.

Their sequences are as follows: Start MO1, 5' -ACGTTGTCA TAAAATGGCATCTTGC-3'; Start MO2, 5' -TGGCATCTTGC GTGTTTTGTGAAGT-3'; Start MO3, 5'-CTTAATGTATGAT CGGAGCGGCGCG-3'; Splice MO1， 5'-GTACAGACCTTGT GGTAATTGGCAC-3'; Splice MO2, 5'-CAGATTGAACTCAC TCATGTCGAAT- $3^{\prime}$.

The start MOs did not produce any effects when injected into wild-type embryos, nor were they able to modify the igu mutant phenotype, indicating that they are incapable of inhibiting igu mRNA translation. The splice MOs were used at a concentration of $1 \mathrm{mM}$ (0.5 $\mathrm{mM}$ when they were used in combination), and $\sim 3 \mathrm{~nL}$ of the MO solution was injected into each fertilized egg.

Embryo injections, in situ hybridization, and antibody labeling

Injection of DNA constructs and in vitro-synthesized mRNA, in situ hybridization, and antibody labeling were done following routine procedures. Probes for forkhead domain 4 ( fkd4; Odenthal and Nusslein-Volhard 1998), gli1 (Karlstrom et al. 2003), and ptc1 (Concordet et al. 1996), the slow myosin heavy chain (MyHC) antibody mAbF59, anti-Eng antibody mAb 4D9, antiProxl antibodies, MOs against zebrafish Su(fu), and gli2 (Wolff et al. 2003, and references therein) as well as capped mRNA expression constructs for shh (Krauss et al. 1993), dnpka, cpka (Concordet et al. 1996), and $\beta$-galactosidase (Schilling et al. 1999) have all been described previously. A full-length zebrafish Su(fu) cDNA (Wolff et al. 2003) was subcloned into the SP64T expression vector. For expressing $\mathrm{N}$-terminal GFP-tagged fulllength wild-type and the igu ${ }^{t s 294 e}$-specific mutant version of the Igu protein, the respective cDNAs were fused in frame with GFP in the pCS2 vector provided by J. Miller (Howard Hughes Medical Institute, University of Washington Medical School, Seattle, WA). Approximately $3 \mathrm{~nL}$ of $0.5 \mathrm{mg} / \mathrm{mL}$ of syntheticcapped mRNA derived from in vitro transcription reactions of the various constructs were injected into each embryo. AntiGFP antibodies (Abcam) were used for amplification of the GFP signal from the tagged Igu proteins, and the preparations were 
counterstained with the DNA-binding dye ToPro-3 to highlight the nuclei. Cyclopamine samples were purchased from Toronto Research Chemicals and used at a concentration of $100 \mu \mathrm{M}$ as described previously (Wolff et al. 2003).

\section{Acknowledgments}

We thank F. Wilson and L. Gleadall for help with fish husbandry; F. van Bebber and S. Glaser for assistance with genetic mapping; C. Davidson, S. Geiger-Rudolph, B.C. Lee, and S.Y. Tay for excellent technical assistance; N. Hopkins for smu mutant fish; the Sanger Institute zebrafish genome sequencing consortium for sequencing and annotation of genomic clones; F. Stockdale, S. Tomarev, and the Developmental Studies Hybridoma Bank for antibodies; J. Miller and R. Karlstrom for plasmids; C. Smythe for pointing out the NES; F. Maderspacher for comments on drafts of the manuscript; and C. Nüsslein-Volhard for her interest and support. This work was funded by a Wellcome Trust program grant (P.W.I.); the Max-Planck Institut für Entwicklungsbiologie and the German Human Genome Project (P.H. and R.G.); the Deutsche Forschungsgemeinschaft (C.W.); and the Institute of Molecular and Cell Biology and the Agency for Science, Technology, and Research, Singapore (S.R.). Confocal microscope facilities were funded by the Yorkshire Cancer Research; the Institute of Molecular and Cell Biology; and the Agency for Science, Technology, and Research. We dedicate this work to the memory of our late friend and colleague, P. Haffter.

The publication costs of this article were defrayed in part by payment of page charges. This article must therefore be hereby marked "advertisement" in accordance with 18 USC section 1734 solely to indicate this fact.

\section{References}

Blagden, C., Currie, P.D., Ingham, P.W., and Hughes, S.M. 1997. Notochord induction of zebrafish slow muscle is mediated by Sonic Hedgehog. Genes \& Dev. 11: 2163-2175.

Brand, M., Heisenberg, C.P., Warga, R.M., Pelegri, F., Karlstrom, R.O., Beuchle, D., Picker, A., Jiang, Y.J., Furutani-Seiki, M., van Eeden, F.J., et al. 1996. Mutations affecting development of the midline and general body shape during zebrafish embryogenesis. Development 123: 129-142.

Buttitta, L., Mo, R., Hui, C.C., and Fan, C.M. 2003. Interplays of Gli2 and Gli3 and their requirement in mediating Shh-dependent sclerotome induction. Development 130:62336243.

Caspary, T., Garcia-Garcia, M.J., Huangfu, D., Eggenschwiler, J.T., Wyler, M.R., Rakeman, A.S., Alcorn, H.L., and Anderson, K.V. 2002. Mouse Dispatched homolog1 is required for long-range, but not juxtacrine, Hh signaling. Curr. Biol. 12: $1628-1632$

Chen, W., Burgess, S., and Hopkins, N. 2001. Analysis of the zebrafish smoothened mutant reveals conserved and divergent functions of Hedgehog activity. Development 128: 2385-2396.

Cheng, S.Y. and Bishop, J.M. 2002. Suppressor of Fused represses Gli-mediated transcription by recruiting the SAP18-mSin 3 corepressor complex. Proc. Natl. Acad. Sci. 99: 5442-5447.

Chiang, C., Litingtung, Y., Lee, E., Young, K.E., Corden, J.L., Westphal, H., and Beachy, P.A. 1996. Cyclopia and defective axial patterning in mice lacking Sonic hedgehog gene function. Nature. 383: 407-413.

Chuang, P.T. and McMahon, A.P. 1999. Vertebrate Hedgehog signaling modulated by induction of a Hedgehog-binding protein. Nature 397: 617-621.
Chuang, P.T., Kawcak, T., and McMahon, A.P. 2003. Feedback control of mammalian Hedgehog signaling by the Hedgehogbinding protein, Hip1, modulates Fgf signaling during branching morphogenesis of the lung. Genes \& Dev. 17: 342-347.

Concordet, J.-P., Lewis, K.E., Moore, J.W., Goodrich, L.V., Johnson, R.L., Scott, M.P., and Ingham, P.W. 1996. Spatial regulation of a zebrafish patched homologue reflects the roles of Sonic Hedgehog and Protein Kinase A in neural tube and somite patterning. Development 122: 2835-2846.

Currie, P.D. and Ingham, P.W. 1996. Induction of a specific muscle cell-type by a Hedgehog-like protein in zebrafish. Nature 382: 452-455.

Ding, Q., Fukami, S., Meng, X., Nishizaki, Y., Zhang, X., Sasaki, H., Dlugosz, A., Nakafuku, M., and Hui, C. 1999. Mouse Suppressor of Fused is a negative regulator of Sonic Hedgehog signaling and alters the subcellular distribution of Glil. Curr. Biol. 9: 1119-1122.

Du, S.J., Devoto, S.H., Westerfield, M., and Moon, R.T. 1997. Positive and negative regulation of muscle cell identity by members of the hedgehog and TGF $\beta$ gene families. I. Cell Biol. 139: 145-156.

Eggenschwiler, J.T., Espinoza, E., and Anderson, K.V. 2001. Rab23 is an essential negative regulator of the mouse Sonic Hedgehog signaling pathway. Nature 412: 194-198.

Goodrich, L.V., Milenkovic, L., Higgins, K.M., and Scott, M.P. 1997. Altered neural cell fates and medulloblastoma in mouse patched mutants. Science. 277: 1109-1113

Hammerschmidt, M., Bitgood, M.J., and McMahon, A.P. 1996. Protein kinase $\mathrm{A}$ is a common negative regulator of Hedgehog signaling in the vertebrate embryo. Genes \& Dev. 10: 647-658.

Huangfu, D., Liu, A., Rakeman, A.S., Murcia, N.S., Niswander, L., and Anderson, K.V. 2003. Hedgehog signaling in the mouse requires intraflagellar transport proteins. Nature 426: $83-87$.

Ingham, P.W. and McMahon, A.P. 2001. Hedgehog signaling in animal development: Paradigms and principles. Genes \& Dev. 15: 3059-3087.

Kalderon, D. 2004. Hedgehog signaling: Costal-2 bridges the transduction gap. Curr. Biol. 14: R67-R69.

Karlstrom, R.O., Trowe, T., Klostermann, S., Baier, H., Brand, M., Crawford, A.D., Grunewald, B., Haffter, P., Hoffmann, H., Meyer, S.U., et al. 1996. Zebrafish mutations affecting retinotectal axon pathfinding. Development 123: 427-438.

Karlstrom, R.O., Talbot, W.S., and Schier, A.F. 1999. Comparative synteny cloning of zebrafish you-too: Mutations in the Hedgehog target gli2 affect ventral forebrain patterning. Genes \& Dev. 13: 388-393.

Karlstrom, R.O., Tyurina, O.V., Kawakami, A., Nishioka, N., Talbot, W.S., Sasaki, H., and Schier, A.F. 2003. Genetic analysis of zebrafish gli1 and gli2 reveals divergent requirements for gli genes in vertebrate development. Development 130: 1549-1564.

Kawakami, T., Kawcak, T., Li, Y.J., Zhang, W., Hu, Y., and Chuang, P.T. 2002. Mouse dispatched mutants fail to distribute hedgehog proteins and are defective in hedgehog signaling. Development 129: 5753-5765.

Kogerman, P., Grimm, T., Kogerman, L., Krause, D., Unden, A.B., Sandstedt, B., Toftgard, R., and Zaphiropoulos. 1999. Mammalian Suppressor of Fused modulates nuclear-cytoplasmic shuttling of Gli-1. Nat. Cell Biol. 1:312-319.

Kondoh, H., Uchikawa, M., Yoda, H., Takeda, H., FurutaniSeiki, M., and Karlstrom, R.O. 2000. Zebrafish mutations in Gli-mediated Hedgehog signaling lead to lens transdifferentiation from the adenohypophysis anlage. Mech. Dev. 
Wolff et al.

96: $165-174$.

Krauss, S., Concordet, J.-P., and Ingham, P.W. 1993. A functionally conserved homologue of the Drosophila segment polarity gene hedgehog is expressed in tissues with polarizing activity in zebrafish embryos. Cell 75: 1431-1444.

Ma, Y., Erkner, A., Gong, R., Yao, S., Taipale, J., Basler, K., and Beachy, P.A. 2002. Hedgehog-mediated patterning of the mammalian embryo requires transporter-like function of dispatched. Cell 111: 63-75.

Matise, M.P., Epsteinm, D.J., Park, H.L., Platt, K.A., and Joyner, A.L. 1998. Gli2 is required for induction of floor plate and adjacent cells, but not most ventral neurons in the mouse central nervous system. Development. 125: 2759-2770.

McMahon, A.P., Ingham, P.W., and Tabin, C. 2003. The developmental roles and clinical significance of Hedgehog signaling. Curr. Topics Dev. Biol. 53: 1-114.

Mo, R., Freer, A.M., Zinyk, D.L., Crackower, M.A., Michaud, J., Heng, H.H., Chik, K.W., Shi, X.M., Tsui, L.C., Cheng, S.H., et al. 1997. Specific and redundant functions of Gli2 and Gli3 zinc finger genes in skeletal patterning and development. Development 124: 113-123.

Moore, F.L., Jaruzelska, J., Fox, M.S., Urano, J., Firpo, M.T., Turek, P.J., Dorfman, D.M., and Pera, R.A. 2003. Human Pumilio-2 is expressed in embryonic stem cells and germ cells and interacts with DAZ (Deleted in Azoospermia) and DAZ-like proteins. Proc. Nat1. Acad. Sci. 100: 538-543.

Motoyama, J., Milenkovic, L., Iwama, M., Shikata, Y., Scott, M.P., and Hui, C.C. 2003. Differential requirement for Gli2 and Gli3 in ventral neural cell fate specification. Dev. Biol. 259: $150-161$.

Nakano, Y., Kim, R., Kawakami, A., Roy, S., Schier, A.F., and Ingham, P.W. 2004. Inactivation of dispatched1 by the chameleon mutation disrupts Hedgehog signaling in the zebrafish embryo. Dev. Biol. 269: 381-392.

Odenthal, J. and Nüsslein-Volhard, C. 1998. fork head domain genes in zebrafish. Dev. Genes Evol. 208: 245-258.

Odenthal, J., van Eeden, F.J., Haffter, P., Ingham, P.W., and Nüsslein-Volhard, C. 2000. Two distinct cell populations in the floor plate of the zebrafish are induced by different pathways. Dev. Biol. 219: 350-363.

Park, H.L. and Bai, C. 2000. Mouse Gli1 mutants are viable but have defects in SHH signaling in combination with a Gli2 mutation. Development 127: 1593-1605.

Schauerte, H.E., van Eeden, F.J., Fricke, C., Odenthal, J., Strähle, U., and Haffter, P. 1998. Sonic hedgehog is not required for the induction of medial floor plate cells in the zebrafish. Development 125: 2983-2993.

Schilling, T., Concordet, J.-P., and Ingham, P.W. 1999. Regulation of left-right asymmetries in the zebrafish by Shh and BMP4. Dev. Biol. 210: 277-287.

van Eeden, F.J., Granato, M., Schach, U., Brand, M., FurutaniSeiki, M., Haffter, P., Hammerschmidt, M., Heisenberg, C.P., Jiang, Y.J., Kane, D.A., et al. 1996. Mutations affecting somite formation and patterning in the zebrafish, Danio rerio. Development 123: 153-164.

Varga, Z.M., Amores, A., Lewis, K.E., Yan, Y.L., Postlethwait, J.H., Eisen, J.S., and Westerfield, M. 2001. Zebrafish smoothened functions in ventral neural tube specification and axon tract formation. Development 128: 3497-3509.

Wolff, C., Roy, S., and Ingham, P.W. 2003. Multiple muscle cell identities induced by distinct levels and timing of Hedgehog activity in the zebrafish embryo. Curr. Biol. 13: 1169-1181.

Zhang, X.M., Ramalho-Santos, M., and McMahon, A.P. 2001. Smoothened mutants reveal redundant roles for Shh and Ihh signaling including regulation of $\mathrm{L} / \mathrm{R}$ asymmetry by the mouse node. Cell 105: 781-792. 


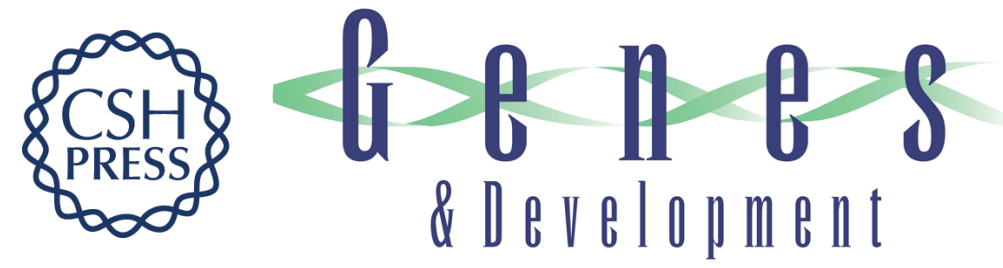

\section{iguana encodes a novel zinc-finger protein with coiled-coil domains essential for Hedgehog signal transduction in the zebrafish embryo}

Christian Wolff, Sudipto Roy, Katharine E. Lewis, et al.

Genes Dev. 2004, 18:

Access the most recent version at doi:10.1101/gad.296004

Supplemental http://genesdev.cshlp.org/content/suppl/2004/06/16/296004.DC1
Material

References This article cites 39 articles, 19 of which can be accessed free at:

http://genesdev.cshlp.org/content/18/13/1565.full.html\#ref-list-1

License

Email Alerting Receive free email alerts when new articles cite this article - sign up in the box at the top

Service

right corner of the article or click here.

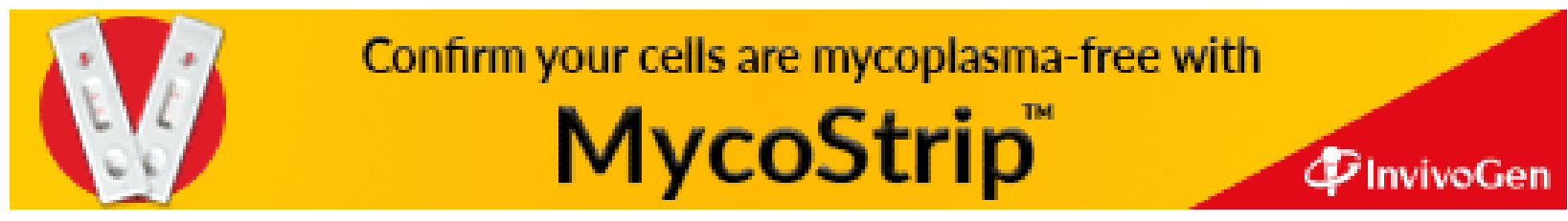

